\title{
Identifikasi Faktor Resiko Yang Mempengaruhi Kinerja Waktu Pelaksanaan Konstruksi Gedung Secara Swakelola Studi Kasus : Pembangunan RKB Sekolah SD dan SMP Kota Bukittnggi
}

\author{
Deddy Kurniawan \\ Fakultas Teknik, Universitas Muhammadiyah Sumatera Barat \\ email: deddykurniawan@umsb.ac.id
}

\begin{abstract}
Proyek konstruksi memiliki sejumlah resiko yang bervariatif, terutama pada proyek swakelola dengan melibatkan banyak pihak, dan memakai berbagai macam sumberdaya, serta menghadapi banyak masalah ketidakpastian dan resiko, jika terjadi dapat mengurangi kerugian waktu yang dapat menjadikan proyek tertunda. Tujuan dari penelitian ini adalah untuk mengetahui faktor- faktor resiko yang mempengaruhi kinerja waktu pelaksanaan konstruksi gedung secara swakelola pada proyek pembangunan RKB sekolah. Proses didalam manajemen resiko proyek adalah identifikasi faktor-faktor resiko, analisa resiko, evaluasi resiko, dan tindakan mengelola resiko. Penelitian untuk mengetahui faktor-faktor resiko dilakukan secara kualitatif, dengan menganalisa data persepsi yang didapat dari kuesioner dengan responden pemilik proyek, tim pelaksana dan tim perencana/pengawas pembangunan RKB sekolah di kota Bukittinggi tahun anggaran 2018. Analisa data diolah dengan statistik deskriptif, Analytic Hierarchy Process (AHP), dan analisa level resiko, untuk mendapatkan rangking faktor. Korelasi nonparametris dilakukan dengan korelasi Spearman. Hasil analisa data menunjukkan ada tujuh faktor resiko utama yang berpengaruh terhadap kinerja waktu pelaksanaan konstruksi gedung secara swakelola pada proyek pembangunan RKB sekolah di Bukittinggi, yaitu : Kemampuan dan kecakapan pelaksana, rangking 1 (14.168\%); Singkatnya waktu pekerjaan, rangking 2 (13.562\%); Manajemen proyek yang kurang pengalaman, rangking 3 (12.529\%); Perpajakan, rangking 4 (11.230\%); Gangguan cuaca, rangking 5 (11.046\%); Tenaga kerja dan produktifitas peralatan, rangking 6 (11.039\%); dan Perkiraan Bill of Quantity yang kurang akurat, rangking 7 (10.314\%). Dari analisa korelasi nonparametris didapat bahwa faktor resiko berkorelasi dengan kinerja waktu yang dapat menurunkan kinerja waktu proyek.
\end{abstract}

Kata kunci : Faktor-Faktor Resiko, Kinerja Waktu, dan Proyek Swakelola

\section{PENDAHULUAN}

Proyek konstruksi memiliki sejumlah resiko yang bervariatif, terutama pada proyek swakelola dengan melibatkan banyak pihak, dan memakai berbagai macam sumberdaya, serta menghadapi banyak masalah ketidakpastian dan resiko, jika terjadi dapat mengurangi kerugian waktu yang dapat menjadikan proyek tertunda. Tujuan dari penelitian ini adalah untuk mengetahui faktorfaktor resiko yang mempengaruhi kinerja waktu pelaksanaan konstruksi gedung secara swakelola pada proyek pembangunan RKB sekolah

\section{METODE PENELITIAN}

Survei pada penelitian ini dilakukan pada proyek pembangunan RKB sekolah yang dilaksanakan secara swakelola dibangun di kota Bukittinggi. Kajian akan dilakukan pada proyek pembangunan RKB sekolah yang bersumber dari dana DAK tahun 2018

Objek penelitian difokuskan pada faktor- faktor resiko yang mempengaruhi kinerja waktu pelaksanaan konstruksi pada proyek pembangunan RKB sekolah secara swakelola.

Subjek pada penelitian ini adalah 5 orang pakar (ahli) yang sudah berpengalaman dalam pelaksanaan proyek pengembangan gedung sekolah terutama gedung sekolah yang dikerjakan secara swakelola dan responden terdiri dari stakholder yaitu Owner (kepala sekolah), pelaksana proyek (Tim Pembangunan) dan Perencana/Pengawas proyek (Tim Perencana \& Pengawas)

\section{Metode Pengumpulan Data}

Data yang dikumpulkan adalah berupa data sekunder dan data primer.

\section{Data Sekunder}

Data sekunder berupa dokumen surat 
perjanjian kerjasama antara PPK dengan Kepala Sekolah dan jadwal proyek dari sejumlah sekolah yang mendapat bantuan proyek pembangunan RKB sekolah dari dana APBN.

\section{Data Primer}

Data primer berupa faktor-faktor resiko yang berpengaruh terhadap pelaksanaan proyek pembangunan RKB sekolah secara swakelola berdasarkan kajian pustaka adalah perencanaan, pelaksanaan, pengawasan, dan kebijakan/ wewenang owner, yang kemudian akan dipecah kembali menjadi beberapa bagian yang kita jadikan variabel bebas $(\mathrm{X})$,

\section{Metode Analisa Data}

Adapun langkah-langkah yang dilaksanakan pada data tahap I adalah :

a. Validasi

Validitas dilakukan untuk menguji apakah pertanyaan yang diberikan mencerminkan apa yang diteliti atau mampu mengukur elemen faktor dalam penelitian. Uji validitas menggunakan construct validity dimana korelasi yang tinggi menunjukan bahwa alat ukur mampu mencerminkan faktor-faktor dalam penelitian. Pengujian validitas dilakukan dengan analisa faktor dimana nilai faktor loadings pada component matrixs merupakan distribusi kesemua item dalam bentuk satu faktor. Angka-angka yang tercipta merupakan factor loadings yang menunjukan besarnya korelasi antara faktor dengan elemen pembentuknya. Setiap faktor apabila item loadings> 0,55 maka elemen faktor dinyatakan valid dan nilai eigen value $<$ 1 maka faktor tersebut dibuang (Chang, 2002).

\section{b. Analisa deskriptif}

Analisa ini memiliki kegunaan untuk menyajikan karakteristik tertentu suatu data dari sampel tertentu. Analisa ini memungkinkan peneliti mengetahui secara cepat gambaran sekilas dan ringkas dari data yang didapat. nilai mean yang berarti nilai rata-rata, dan nilai median yang diperoleh dengan cara mengurutkan semua data. Hasil data deskriptif akan disajikan dalam masingmasing variabel.

\section{c. Analisa resiko}

Analisa level resiko dilakukan dengan indeks level resiko, dimana indeks level resiko adalah perkalian antara frekuensi dan dampak. Indeks level resiko dikelompokkan ke dalam empat kelas sesuai Tabel 3.1. Rentang kelas diketahui dari bobot yang paling tinggi dikurangi dengan bobot yang paling rendah dan hasilnya dibagi dengan banyaknya kelas. Hasil dari analisa resiko ini digunakan untuk mereduksi jumlah variabel, yang diambil adalah variabel resiko yang mempunyai indeks level resiko signifikan dan tinggi.

Tabel 1. Level Resiko

\begin{tabular}{|c|c|c|}
\hline Symbol & $\begin{array}{r}\text { Level } \\
\text { Resiko }\end{array}$ & Keterangan \\
\hline $\mathrm{H}$ & $\begin{array}{r}\text { Res } \\
\text { iko }\end{array}$ & $\begin{array}{c}\text { Perlu } \\
\text { pengamatan }\end{array}$ \\
\hline $\mathrm{S}$ & $\begin{array}{r}\text { Resiko } \\
\text { signifik }\end{array}$ & $\begin{array}{c}\text { Perlu ditangani oleh } \\
\text { manajer }\end{array}$ \\
\hline $\mathrm{M}$ & $\begin{array}{r}\text { Resiko } \\
\text { sedang }\end{array}$ & $\begin{array}{c}\text { Resiko rutin, } \\
\text { ditangani }\end{array}$ \\
\hline $\mathrm{L}$ & $\begin{array}{r}\text { Resiko } \\
\text { rendah }\end{array}$ & $\begin{array}{r}\text { Resiko rutin, ada } \\
\text { dianggaran }\end{array}$ \\
\hline
\end{tabular}

Sumber :

Duffield (2003)

\section{d. Analisa Hierarchy Process (AHP)}

Analisa AHP adalah salah satu metode yang digunakan pada penelitian ini untuk mengetahui bobot atau nilai faktor resiko yang berpengaruh pada kinerja waktu Proyek pengembangan SMK di Aceh. Menurut Saaty (1980) AHP adalah salah satu metode yang digunakan dalam menyelesaikan masalah yang mengandung banyak kriteria (Multi-Criteria Decision Making).

Perhitungan AHP, dimulai dengan perlakukan normalisasi matriks, perhitungan konsistensi matriks, konsistensi hirarki dan tingkat akurasi, perhitungan nilai lokal pengaruh, dan perhitungan nilai lokal frekwensi, dari hasil perhitungan ini akan didapat nilai akhir resiko (goal) dan peringkat berdasarkan bobot hasil perhitungan.

\section{HASIL DAN PEMBAHASAN}

\section{Kuesioner Tahap Satu}

Pengumpulan Data Tahap Satu dilakukan analisa secara deskriptif sehingga didapat nilai rata-rata minimum 5,6, maximum 10,8, mean 9,20, modus 9.40, median 9.60, dan standar deviasi 1.254. Variabel yang direduksi adalah nilai di bawah mean. 
Selanjutnya berdasarkan analisa level resiko untuk empat kelas yaitu L ( Low ), M ( Medium ), S (Significant), dan H (High ), dimana nilai terendah 5.6, nilai terbesar adalah 10.8 , rentangan 5.2 , dan batas kelas 1.3 , berdasarkan tujuan manajemen resiko dimana proyek fokus pada level resiko $S$ (Significant ) dan H (High) untuk meningkatkan kinerja waktu proyek, variabel yang tereduksi adalah variabel dengan level resiko L (Low ) dan M ( Medium ), sehingga dari 38 variabel yang diusulkan ke pakar, hasil olah data didapat 30 variabel yang akan digunakan pada pengumpulan data tahap kedua.

Hasil analisa deskriptif akan disajikan dalam masing-masing variable. Untuk variabel $\mathrm{Y}$, yang merupakan kinerja waktu proyek, diperoleh nilai modus sebesar 3 yang berarti kinerja waktu proyek rata-rata (terlambat $-8 \%$ atau terlambat 4 minggu dari skedul).

\section{Tabel 2. Hasil Analisa Deskriptif Variabel} Kinerja Waktu (Y)

\begin{tabular}{|r|r|r|}
\hline \multirow{2}{*}{$\mathrm{N}$} & Valid & 48 \\
\cline { 2 - 3 } & Missing & 0 \\
\hline \multicolumn{2}{|c|}{ Mea } & 3.00 \\
\hline \multicolumn{2}{|c|}{ Media } & 3.00 \\
\hline \multicolumn{2}{|c|}{ Mod } & 3 \\
\hline \multicolumn{2}{|c|}{} \\
\hline
\end{tabular}

Keterangan :

- $\mathrm{N}$ atau jumlah data yang valid (sah untuk diproses) adalah 48 buah, sedangkan data yang hilang (Missing) adalah nol. disini berarti semua data diproses

- Mean adalah nilai rata-rata jawaban responden yaitu : $\mathrm{Y}=\sum \mathrm{Yi} / \mathrm{N}$

- Median adalah nilai tengah yang dicari menurut ranking.

- Mode dari suatu set pengamatan, adalah nilai yang muncul terbanyak, atau yang mempunyai frekuensi pemunculan yang terbanyak

Hasil analisa data menggunakan AHP dan Analisa level resiko maka didapat 7 variabel yang masuk pada level significant risk (S) dan High risk ( $\mathrm{H}$ ), masing-masing faktor resiko ini berkorelasi kuat terhadap kinerja waktu. Adapun faktor-faktor resiko tersebut adalah :

a. $\begin{aligned} & \text { Kemampuan dan } \\ & \text { pelaksana }(\mathrm{X} 12)=\end{aligned}$
$\begin{aligned} & \text { kecakapan } \\ & (14.168 \%)\end{aligned}$
b. Singking 1
Singa waktu pekerjaan $(\mathrm{X} 1)=$ rangking $2(13.562 \%)$

c. Manajemen proyek yang kurang pengalaman $(\mathrm{X} 28)=$ rangking $3(12.529 \%)$

d. Perpajakan $(\mathrm{X} 21)=$ rangking 4 (11.230\%)

e. Gangguan cuaca (X14) = rangking $5(11.046 \%)$

f. Tenaga kerja dan produktifitas peralatan (X9) $=$ rangking 6 (11.039\%)

g. Perkiraan Bill of Quantity yang kurang akurat $(X 5)=$ rangking 7 $(10.314 \%)$

\section{Analisis Validasi Tahap 2}

Analisa data untuk tahap ketiga dilaksanakan untuk validasi ke pakar. Variabel hasil penelitian yang telah diolah dan dianalisa, yaitu faktor-faktor resiko utama, dibawa kepakar untuk validasi, apakah pakar setuju dengan hasil penelitian, jika mayoritas dari pakar berpendapat setuju maka penelitian ini dikatakan valid. Kemudian pakar diminta komentarnya mengenai tindakan yang perlu dilakukan terhadap faktor resiko utama.

Analisa validasi data tahap 2 ini dilakukan dengan mengajukan kuesioner terhadap pakar yang memenuhi persyaratan untuk mengetahui pendapat mereka tentang hasil yang didapat. Pakar yang dihubungi pada validasi tahap ini, sama dengan pakar pada kuesioner tahap pertama. Para pakar tersebut memberikan penilaian dan masukan mengenai tindakan pencegahan dan kereksi terhadap 7 (tujuh) variabel dominan yang berpengaruh terhadap kinerja waktu. Analisa validasi pakar ini tidak mempermasalahkan urutan tingkat level resiko (rangking) dari hasil perhitungan atau analisa AHP, demikian pula jumlah variabel dominan tidak mengalami penambahan atau pengurangan.

Hasil dari penilaian dan masukan berupa tindakan pencegahan dan koreksi 
terhadap 7 (tujuh) variabel dominan tersebut secara keseluruhan, 5 (lima) orang pakar/ahli telah menyatakan menyetujui bahwa 7 (tujuh) variabel dominan tersebut yang dapat mempengaruhi kinerja waktu secara keseluruhan pada pelaksanaan konstruksi gedung secara swakelola untuk proyek pembangunan RKB sekolah di Bukittinggi. Para pakar tidak diminta untuk memberikan penilaian atas rangking yang merupakan output dari analisa data. Dengan demikian hasil penelitian ini dapat dikatakan valid, dimana dari 30 (tiga puluh) variabel didapat 7 (tujuh) variabel dominan yang berpengaruh pada kinerja waktu pelaksanaan konstruksi pada proyek pembangunan RKB sekolah. Agar variabel- variabel resiko tersebut bisa dikelola dan tidak berdampak luas terhadap kinerja waktu, diperlukan tindakan nyata dari pihak sekolah yang menerima bantuan proyek pembangunan RKB sekolah.

\section{Pembahasan}

Pembahasan dari 7 (tujuh) faktor dominan yang berpengaruh pada kinerja waktu pada pelaksanaan konstruksi gedung secara swakelola pada proyek pembangunan RKB sekolah di Bukittinggi dapat dikelompokkan ke dalam 3 (tiga) kelompok faktor yaitu Perencanaan, Pelaksanaan, dan Kebijakan/wewenang pemilik. Ketiga kelompok faktor tersebut dapat dijabarkan sebagai berikut :

a. Tahap Perencanaan, terdapat 2 (dua) faktor resiko, yaitu singkatnya waktu pekerjaan dan perkiraan Bill of Quantity (BQ) yang kurang akurat.

b. Tahap Pelaksanaan, terdapat 4 (empat) faktor resiko, yaitu tenaga kerja dan produktifitas peralatan, kemampuan dan kecakapan pelaksana, gangguan cuaca, dan perpajakan.

c. Kebijakan / wewenang pemilik, terdapat 1 (satu) faktor resiko, yaitu manajemen proyek yang kurang pengalaman

Tahapan kelompok faktor dan variabel dominan secara terinci dapat dilihat pada Tabel 2 di bawah ini

Tabel 3. Variabel Dominan Pada Yang Berpengaruh Terhadap Kinerja

\begin{tabular}{|c|c|c|c|}
\hline No & Kelompok Faktor & $\begin{array}{c}\text { Nama } \\
\text { Variabe }\end{array}$ & $\begin{array}{c}\text { Variabel Dominan Yang Berpengaruh Terhadap } \\
\text { Kineria }\end{array}$ \\
\hline \multirow{2}{*}{1} & \multirow{2}{*}{ Perencanaan } & $\mathrm{X} 1$ & Singkatnya waktu pekerjaan \\
\hline & & $\mathrm{X} 5$ & Perkiraan Bill of Quantity $(B Q)$ yang kurang akurat \\
\hline \multirow{4}{*}{2} & \multirow{4}{*}{ Pelaksanaan } & $\mathrm{X} 9$ & Tenaga Kerja dan Produktifitas Peralatan \\
\hline & & $\mathrm{X} 12$ & Kemampuan dan Kecakapan Pelaksana \\
\hline & & $\mathrm{X} 14$ & Gangguan \\
\hline & & $\mathrm{X} 21$ & Perpajaka \\
\hline 3 & $\begin{array}{c}\text { Kebijakan/wewenan } \\
\mathrm{g}\end{array}$ & $\mathrm{X} 28$ & Manajemen proyek yang kurang pengalaman \\
\hline
\end{tabular}

Dari hasil penelitian ini dapat dibahas mengenai tindakan koreksi pada faktor-faktor utama yang dominan berpengaruh terhadap kinerja waktu pada proyek pembangunan RKB sekolah di Bukittinggi.
Tindakan pencegahan dan koreksi dalam pembahasan ini sesuai dengan input dari pakar pada validasi variabel data tahap tiga dan diselaraskan dengan referensi dapat dilihat pada tabel dibawah ini.

Tabel 2. Tindakan Koreksi terhadap Faktor-faktor Utama

\begin{tabular}{|c|c|c|}
\hline No & Faktor-faktor resiko & Tindakan Koreksi \\
\hline$\overline{c 172}$ & & $\begin{array}{r}\text { ISSN 2599-2081 } \\
\text { EISSN 2599-2090 }\end{array}$ \\
\hline
\end{tabular}




\begin{tabular}{|c|c|c|}
\hline \multirow{2}{*}{1} & \multirow{2}{*}{$\begin{array}{l}\text { Kemampuan dan kecakapan } \\
\text { pelaksana } \\
(\mathrm{X} 12)\end{array}$} & $\begin{array}{l}\text { Membentuk tim pelaksana yang memiliki latar } \\
\text { belakang T. Sipil / Arsitektur }\end{array}$ \\
\hline & & Sudah pernah menangani proyek konstruksi \\
\hline & & $\begin{array}{l}\text { Pada saat penandatanganan MOU, sudah } \\
\text { dipastikan dana } \\
\text { proyek akan turun, olehkarenannya, pelaksanaan } \\
\text { proyek sudah dapat dikerjakan meskipun uang } \\
\text { belum masuk kerekening sekolah dengan } \\
\text { cara melakukan kerjasama dengan pihak toko } \\
\text { atau hantuan dana nada Komite sekolah. Hal ini }\end{array}$ \\
\hline & & $\begin{array}{l}\text { Mempekerjakan pelaksana/ tukang yang } \\
\text { berpengalaman dan }\end{array}$ \\
\hline \multirow[b]{2}{*}{3} & \multirow[b]{2}{*}{$\begin{array}{l}\text { Manajemen proyek yang } \\
\text { kurang pengalaman (X28) }\end{array}$} & $\begin{array}{l}\text { Owner diwajibkan untuk mengikuti BIMTEK } \\
\text { pelaksanaan }\end{array}$ \\
\hline & & $\begin{array}{l}\text { Sangsi diberikan kepada kepala SMK yang tidak } \\
\text { mengikuti BIMTEK, yaitu dengan mengalihkan } \\
\text { bantuan pembangunan SMK ke sekolah lain. }\end{array}$ \\
\hline \multirow[b]{2}{*}{4} & \multirow[b]{2}{*}{ Perpajakan (X21) } & Memilah Material bangunan yang dikenai pajak \\
\hline & & $\begin{array}{l}\text { Memperhitungkan secara matang pajak } \\
\text { yang harus }\end{array}$ \\
\hline \multirow[t]{2}{*}{5} & \multirow[t]{2}{*}{ Gangguan cuaca (X14) } & $\begin{array}{l}\text { Membuat laporan pemberitahuan tentang } \\
\text { kondisi lapangan } \\
\text { dan meminta perpanjangan waktu pelaksnaan }\end{array}$ \\
\hline & & $\begin{array}{l}\text { Tim pelaksana yang dibentuk harus mampu } \\
\text { mengelola }\end{array}$ \\
\hline \multirow[t]{3}{*}{6} & \multirow{3}{*}{$\begin{array}{l}\text { Tenaga kerja dan produktifitas } \\
\text { peralatan } \\
\text { (X9) }\end{array}$} & $\begin{array}{l}\text { Mendatangkan tenaga kerja dari luar yang } \\
\text { berpengalaman untuk memobilisasi pekerja lokal }\end{array}$ \\
\hline & & $\begin{array}{l}\text { Melakukan pembinaan dan pembekalan kepada } \\
\text { pekerja oleh konsultan perencana sebelum }\end{array}$ \\
\hline & & $\begin{array}{l}\text { Menggunakan peralatan dari pihak lain melalui } \\
\text { penyewaan jika sangat membutuhkan }\end{array}$ \\
\hline \multirow[t]{3}{*}{7} & \multirow[t]{3}{*}{$\begin{array}{l}\text { Perkiraan Bill of Quantity (BQ) } \\
\text { yang kurang akurat (X5) }\end{array}$} & $\begin{array}{l}\text { Review terhadap metode perhitungan dalam } \\
\text { analisa harga }\end{array}$ \\
\hline & & $\begin{array}{l}\text { Membentuk Tim Perencana yang profesional } \\
\text { sesuai dengan } \\
\text { latar belakang keahlian, boleh diambil dari } \\
\text { kalangan SMK yang memiliki jurusan teknik } \\
\text { vano dibutuhkan ataunun dari kalanoan }\end{array}$ \\
\hline & & $\begin{array}{l}\text { Pendidikan tim perencana minimal D3 teknik } \\
\text { sesuai jurusan }\end{array}$ \\
\hline
\end{tabular}

\section{SIMPULAN}

Dari hasil penelitian dapat diambil kesimpulan ;

1) Terdapat faktor-faktor yang mempunyai dampak terhadap kinerja waktu pelaksanaan konstruksi Gedung secara swakelola pada proyek pembangunan RKB sekolah di Bukittinggi, 
faktor-faktor resiko utama tersebut adalah :
a. Kemampuan dan kecakapan pelaksana $(\mathrm{X} 12)=$ rangking 1 $(14.168 \%)$
b. Singkatnya waktu pekerjaan $(\mathrm{X} 1)=$ rangking $2(13.562 \%)$
c. Manajemen proyek yang kurang pengalaman (X28) = rangking $3(12.529 \%)$
d. Perpajakan $\quad(\mathrm{X} 21)=$ rangking 4 $(11.230 \%)$
e. Gangguan cuaca $(\mathrm{X} 14)=$ rangking $5(11.046 \%)$
f. Tenaga kerja dan produktifitas peralatan (X9) $=$ rangking $6(11.039 \%)$

g. Perkiraan Bill of Quantity yang kurang akurat $(\mathrm{X} 5)=$ rangking 7 $(10.314 \%)$

2) Dari hasil uji Hipotesis terdapat hubungan (pengaruh) faktor-faktor resiko terhadap kinerja waktu proyek dan faktorfaktor resiko yang ada akan menurunkan kinerja waktu proyek pembangunan RKB sekolah di Bukittinggi.

3) Hasil analisa deskriptif untuk kinerja waktu proyek pembangunan RKB sekolah di Bukittinggi diperoleh nilai modus sebesar 3 yang berarti kinerja waktu proyek rata-rata terlambat < $-8 \%$ atau terlambat 4 minggu atau kurang dari 4 minggu dari skedul.

4) Tindakan koreksi terhadap faktorfaktor resiko yang mempengaruhi kinerja waktu pelaksanaan proyek pembangunan RKB sekolah di Bukittinggi diperlukan untuk mengurangi resiko keterlambatan pekerjaan dan untuk pencapaian efesiensi dan efektifitas pelaksanaan proyek

\section{Saran}

Dari hasil pengamatan dan penelitian dilapangan serta evaluasi terhadap kuesioner, ada beberapa saran yang perlu dikemukakan yaitu:

1. Dari hasil analisis terhadap faktorfaktor resiko utama pada pelaksanaan konstruksi gedung secara swakelola pada proyek pembangunan RKB sekolah yang sangat kuat berkorelasi terhadap menurunnya kinerja waktu proyek. Untuk itu perlu mendapat perhatian yang sangat tinggi terhadap faktor-faktor tersebut dari pihak owner maupun pelaksana dan pihak perencana dan sekaligus melakukan pengontrolan terhadap faktor-faktor tersebut untuk mengefisiensikan waktu pekerjaan proyek.

2. Semua keterbatasan pada penelitian ini hendaknya dapat dilanjutkan pada penelitian berikutnya, yaitu melakukan penelitian terbalik, dengan cara apakah tindakan pencegahan dan koreksi yang ada apabila diterapkan dengan baik dapat secara signifikan meningkatkan kinerja waktu pelaksanaan konstruksi gedung secara swakelola pada proyek pembangunan RKB sekolah secara keseluruhan.

3. Keterbatasan pada penelitian ini diharapkan dapat dilanjutkan/diperdalam pada penelitian berikutnya, karena penelitian ini dilakukan secara umum tanpa mengambil salah satu kasus jenis proyek tertentu. Sehingga diharapkan penelitian selanjutnya dapat dikembangkan pada satu kasus jenis proyek, mengingat proyek bersifat unik.

4. Diharapkan ada feedback dari hasil penelitian ini, sehingga hasil penelitian ini dapat lebih dikembangkan dan disempurnakan, dan dapat dijadikan bahan kajian baik secara akademis maupun praktis guna memecahkan permasalahan dalam proses pelaksanaan gedung secara swakelola pada proyek pembangunan RKB sekolah yang berpengaruh pada kinerja waktu. 


\section{UCAPAN TERIMAKASIH}

Puji syukur penyusun panjatkan kehadapan Allah SWT, karena atas berkat, rahmat dan bimbingan-NYA penyusun dapat menyelesaikan jurnal ilmiah yang berjudul “ Identifikasi factor resiko yang mempengaruhi kinerja waktu pelaksanaan konstruksi secara swakelola (studi kasus : pembangunan RKB sekolah SD dan SMP di kota Bukittinggi) ". Tersusunnya jurnal ilmiah ini tentunya tidak terlepas dari bantuan banyak pihak dalam memberikan bimbingan, pengarahan, petunjuk, bantuan dan informasi. Untuk itu melalui kesempatan ini penulis mengucapkan terima kasih kepada, orang tua, keluarga, teman-teman yang saling mendukung dan membantu menyelesaikan jurnal ilmiah ini.

\section{DAFTAR PUSTAKA}

Ahmed, S.M, Ahmad, R \& Saram, D., 1999. Risk management trends in the Hong Kong construction industry : a comparison of contractors and owners perception. Journal of Engineering, Construction and Architectural Management, 6 .

Arisman, M., 2005. Identifikasi sumber resiko pada proyek EPC (study kasus proyek $A B C, P T X)$, Thesis. Fakultas Teknik Universitas Indonesia.

Al-Bahar, JF dan Crandel, K.C, 1990. Systematic Risk Management Approach for Construction Project. Journal of Construction Engineering and Management, ASCE, Vol. 116, No.3, September.

Australian Standard, AS/NZS 4360, 1999. Risk Management.

B.Mulholand dan J.Christian,1999. Risk Assesment in Constructtion

Schedules, Journal of Construction Engineering \& Management, Vol.1, January/February.

Darmawi, H., 1996. Manajemen Resiko. Jakarta: Bumi Aksara

Djohanputro, B., 2004. Manajemen Resiko Korporat Terintegrasi. PPM.

Ervianto, I.W., 2005. Manajemen Proyek Konstruksi. Yogyakarta: Andi.

Flanagan, R. and Norman, G., 1993. Risk Management and Construction. London: Blackwell Scientific
Publication

Hosen Radian Z. et.al., 2006 Prosedur Manajemen Resiko Proyek. PT. Rekayasa Industri. Kangari, R. 1995. Risk management perceptions and trends of U.S construction. Journal of Construction Engineering and Management, 121. Hal: 422-429.

Ken, R., Risk Management-Managing Standards Home page-1996. 1997. 1998. 2003.

Keputusan Menteri Pendidikan Nasional Nomor 053/u/2001 tahun 2001 Tentang Pedoman Penyusunan Standar Pelayanan Minimal Penyelenggaraan Persekolahan Bidang Pendidikan dasar dan Menengah. Jakarta.

Kog, Y.C, et al., 1999. Key Determinants for Construction Schedule Performance. International Journal of Project Management Vol.17, No.6. Hal: 351359.

Mokoginta, Y.F., 2007. Faktor-faktor resiko yang mempengaruhi pada kinerja waktu pelaksanaan konstruksi proyek pengembangan kampus swasta. Tesis. Teknik Sipil MK. Jakarta: Universitas Indonesia.

Nazir, M., 2003. Metode Penelitian, Jakarta: Ghalia Indonesia.

Peraturan Menteri Pekerjaan Umum Nomor 45/PRT/M/2007 tentang Pedoman Teknis Pembangunan Gedung Negara, Jakarta.

Pedoman Perencanaan Pembangunan Unit Sekolah Baru Sekolah Menengah Kejuruan tahun 2009, Direktorat Pembinaan SMK, Dirjen Manajemen Dasar \& Menengah, Departemen Pendidikan Nasional, Jakarta.

Peraturan Presiden No. 54 Tahun 2010 Tentang Pengadaan Barang/Jasa Pemerintah, CV. Tamita Utama, Jakarta.

Perry, J.G \& Hayes, R.W., 1985. Risk and its Management in Construction Period, Instution of Civil Engineer Procedings.

PMI, 2004. A Guide to Project Management Body of Knowledge, (PMBOK $^{@}$ Guide),Third Edition. Project Management Institute. 
Priyono, H.E., 2003. Pengaruh Identifikasi Faktor Resiko terhadap Kinerja Waktu untuk Pelaksanaan Pembangunan rusun dan apartment. Thesis. Jakarta: Fakultas Teknik Universitas Indonesia.

Ronny, K., 2004. Manajemen Resiko Operasional. PPM.

Saaty \& Vargas, 1994. Decision Making With The Analityc Hierarchy Process. RWS Publications.

Santoso, S., 2010. Mastering SPSS 18. Jakarta: Elex Media Komputindo.

Sitorus, J., 2008. Faktor-faktor Resiko Yang Berpengaruh Terhadap Kinerja Waktu Proyek EPC Gas Di Indonesia. Tesis. Jakarta: Fakultas Teknik Universitas Indonesia.

Sugiono, 2006. Statistika Untuk Penelitian. Bandung: Alfabeta.

Wideman, M., 1992. Project and Program Risk Management, A Guide to Managing Risk and Opportunities. PMI.

Yin, R.K., 1994. Case Study Research ; Design and Methods. USA: Sage Publications Inc 